\title{
Forum
}

\section{ELESI RABUNI}

Assistant Bursar, UPNG, Port Moresby

\section{Transfer of \\ PJR funds \\ from UPNG}

WE ARE IN receipt of your letter dated 28 April 1998 requesting that the balance of the Pacific Journalism Review account SPA 1407 of K1783.42 be transferred to the University of the South Pacific.

Regrettably, we cannot accommodate this request as this Pacific Journalism Review money was given to be managed by the University of Papua New Guinea and we cannot see our way clear to transferring it to another institution.

The South Pacific Centre for Communication and Information in Development (SPCenCIID) has also indicated that they will need this fund.

I hope that you understand our position on this matter.

Vinaka vakalevu.
Editor's note: The University of $P N G$ has effectively hijacked the subscribers' money. The Pacific Journalism Review fund of K1783.42 is not UPNG money - it belongs to the journal.

It is money for library subscriptions and advertising revenue from media organisations paid directly to PJR and held in trust in a special purpose account, SPA 1407, by UPNG on behalf of the journal.

The return of the money has been requested four times over 10 months through the UPNG Bursar's Office and the Registrar, but has not been released. It is also apparent that the fund was "needed" by a department (SPCenCIID) which had nothing to do with the raising of funds for PJR and which was subsequently due to be closed in early 1999 as part of UPNG's controversial restructuring.

Publication of Pacific Journalism Review moved to Fiji in March 1998 and a new trust fund was created with the Bursar's Office at the University of the South Pacific.

Printing of this edition of PJR has been kindly assisted by UNESCO. 